\title{
O PNBE E AS BIBLIOTECAS ESCOLARES DE OURO PRETO - MG
}

\author{
PNBE AND OURO PRETO SCHOOL LIBRARIES - MG
}

\author{
JUNQUEIRA, Renata \\ recellij@gmail.com \\ UNESP- Universidade Estadual Paulista Júlio de Mesquita Filho
}

\begin{abstract}
RESUMO Este artigo tem por objetivo mapear e analisar a ampliação e circulação do acervo das bibliotecas escolares no município de Ouro Preto/MG, a partir da política pública Programa Nacional Biblioteca da Escola - PNBE. Foi realizada uma pesquisa exploratória, por meio de contato e entrevistas com 30 escolas situadas no município. A partir dos dados coletados, realizamos uma pesquisa sobre as práticas de letramento literário que vêm sendo desenvolvidas nesses espaços. Parte-se do princípio de que as bibliotecas escolares são agências de letramentos que têm por função contribuir com os trabalhos realizados por professores para promoção da leitura literária. Os resultados apontam dificuldades de acesso aos livros do PNBE, por professores e alunos, e a falta de uma política interna de divulgação dos livros.

Palavras-chave: Acervos. Bibliotecas escolares. Leitura. PNBE.
\end{abstract}

ABASTRACT This article aims to map and analyze the expansion and circulation of the library of school libraries in the municipality of Ouro Preto / MG, based on the public policy "National Program Library of the School" (PNBE). In this case, an exploratory research was carried out, through contact and interviews with the 30 schools located in the city. From the collected data, we conducted a research on the literary literacy practices that have been developed in these school spaces. It is assumed that school libraries are literacy agencies whose function is to contribute to the work done by teachers to promote literary reading. The results point to difficulties in accessing the PNBE books, by teachers and students, and the lack of an internal policy to disseminate of the books.

Keywords: Collection. PNBE. Reading. School libraries.

\section{INTRODUÇÃO}

Não há dúvida de que um dos maiores desafios colocados atualmente à escola pública brasileira é garantir aos estudantes o domínio da leitura e da escrita, importantes competências e habilidades discutidas na contemporaneidade. Para tanto, algumas ações têm sido implementadas e desenvolvidas no âmbito das políticas públicas para a leitura, como por exemplo, a ampliação dos acervos das bibliotecas escolares. 
O Programa Nacional Biblioteca da Escola - PNBE consiste em uma política pública de ampliação paulatina dos acervos das bibliotecas escolares de todo o Brasil, em todos os segmentos e níveis do ensino: educação infantil, ensino fundamental, ensino médio e educação de jovens e adultos. Em artigo anterior (CORRÊA e PAIVA, 2015) apresentam um breve retrospecto dessas políticas públicas de ampliação dos acervos de bibliotecas escolares. Reproduzimos abaixo parte dessa retrospectiva, com o intuito de historicizar o processo, bem como para contextualização do leitor:

\section{POLíticas pÚblicas de AMPLIAÇÃo de ACERVO E FORMAÇÃo DE LEITORES EM BIBLIOTECAS ESCOLARES}

No Brasil, as ações de promoção e acesso à leitura de livros de literatura são desenvolvidas pelo Ministério da Educação (MEC) desde sua criação em 1930. Entretanto, foi apenas na década de 1980 que a questão da formação de leitores entrou na pauta das políticas públicas e, ainda assim, não de forma prioritária sempre afetadas pela descontinuidade das políticas públicas. Podemos exemplificar essas ações com os seguintes programas: Programa Nacional Sala de Leitura PNSL - 1984 a 1987; Proler - 1992 (em funcionamento até os dias atuais); Próleitura na Formação do Professor - 1992 a 1996; Programa Nacional Biblioteca do Professor - 1994 a 1997 e o Programa Nacional Biblioteca da Escola - PNBE, implantado em 1997, pela Portaria 652 de 16/09/1997.

O PNBE tem como objetivo principal democratizar o acesso a obras de literatura infanto-juvenis, brasileiras e estrangeiras, e a materiais de pesquisa e de referência a professores e alunos das escolas públicas brasileiras. Ao longo da história desse Programa, a distribuição dos livros de literatura tem sido realizada por meio de diferentes ações: em 1998, 1999 e 2000, os acervos foram enviados para as bibliotecas escolares; em 2001, 2002 e 2003, o objetivo era que os alunos tivessem acesso direto a coleções de uso pessoal e também levassem obras representativas da literatura para seus familiares - por isso, essas edições do programa ficaram conhecidas como Literatura em Minha Casa.

A partir de 2005, após inúmeras discussões coordenadas pela Secretaria de Educação Básica - SEB/MEC, o PNBE voltou a distribuição de livros de literatura 
para as bibliotecas escolares. Tal ação significou a retomada da valorização desse espaço, a biblioteca, como promotora da universalização do conhecimento e, também, da universalização do acesso à acervos pelo coletivo da escola.

Em suas últimas edições, o Programa compreendeu a distribuição de acervos literários para todo o ensino básico, incluídas a Educação Infantil e a Educação de Jovens e Adultos, além de periódicos e conjunto de obras de pesquisa e referenciais para professores por meio do programa "PNBE do professor". Houve, também, a seleção de obras específicas nas derivações do PNBE, como "PNBE temático", "PNBE indígena" e "PNBE do campo". O atendimento aos segmentos ocorreu da seguinte forma: nos anos pares foram atendidos: a Educação Infantil, os anos iniciais do Ensino Fundamental e EJA; nos anos ímpares, anos finais do Ensino Fundamental e Ensino Médio.

Desde que o PNBE foi instituído, coube à SEB/MEC a coordenação do processo de avaliação de obras e composição dos acervos de todas as suas edições, num trabalho conjunto com o Fundo Nacional de Desenvolvimento da Educação - FNDE. No ano de 2005, a SEB/MEC passou a realizar esse trabalho em parceria com Universidades Públicas Federais e, para tanto, a partir de 2005, vem selecionando instituições que, sob sua coordenação, executam a avaliação. As instituições interessadas, de posse de edital publicado na página do FNDE, que estabelece as normas e procedimentos a serem seguidos, candidatam-se à instituição parceira na execução desse Programa por meio do encaminhamento de suas propostas, nas quais expõe de modo minucioso o processo de avaliação a ser utilizado.

O resultado desse trabalho é que, ano após ano, desde 1997, dezenas de livros aportam nas escolas públicas do nosso País, endereçados a diferentes segmentos, após um longo e exaustivo processo de avaliação, seleção e aquisição dos acervos. Deste modo, é possível afirmar com certa margem de acerto que os livros estão nas bibliotecas escolares, ou nos cantinhos de leitura, prontos para a circulação e recepção. Mas é bom que se saiba que, na construção e implementação dessa política, inúmeras discussões são travadas e estudos e pesquisas realizados para a sua revisão e aperfeiçoamento. Estudos apresentados por Paiva (2012) mostram que ainda não superamos a fase da distribuição e que ainda temos de trabalhar muito para que os alunos brasileiros tenham acesso, de 
fato, às obras de literatura a eles destinadas, criando condições mínimas, mas fundamentais, para que o processo de formação de leitores literários, de democratização da literatura aconteça.

Além do ponto nodal acima detectado, de falta de uma política específica de formação de leitores, infelizmente a partir de 2015 pelo menos dois projetos de avaliação de acervos para o PNBE foram concluídos, mas os livros não foram comprados e distribuídos pelo MEC para as escolas brasileiras: PNBE indígena e seleção de livros para os segmentos de 2015.

Ainda assim, com a descontinuidade (pelo menos até o presente momento) do projeto, acreditamos ser importante mapear o uso que os livros distribuídos nas edições anteriores do PNBE têm tido nas escolas. Portanto, a fim de conduzir uma pesquisa qualitativa sobre as práticas de leitura em bibliotecas escolares da cidade de Ouro Preto - MG, propusemos realizar uma investigação exploratória sobre esses acervos, pois acreditamos que a circulação dos livros é importante na formação de leitores e em atividades de letramento literário nas escolas.

\section{LEITURA, LETRAMENTO E LETRAMENTO LITERÁRIO}

Conforme indicam os resultados de diferentes avaliações em larga escala, a proficiência média em leitura dos estudantes brasileiros encontra-se em um estágio crítico. De acordo com o Programa Internacional de Avaliação de Alunos (PISA) de

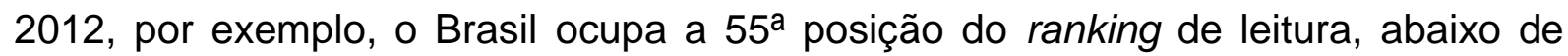
países como Chile, Uruguai, Romênia e Tailândia. Em 2012 o país somou 410 pontos em leitura, estando 86 pontos abaixo da média dos países da Organização para Cooperação e Desenvolvimento Econômico (OCDE). O estudo revela que aproximadamente a metade $(49,2 \%)$ dos alunos brasileiros não chega a alcançar o nível 2 de desempenho na avaliação em leitura, que varia de 0 a 6 . Nesse nível, os alunos ainda não são capazes, por exemplo, de identificar informações de um texto ou de estabelecer relações entre diferentes partes dele.

Certamente são diversas as formas de enfrentamento desse desafio: maior investimento em educação, valorização do magistério, oportunidades de formação inicial e continuada dos docentes, dentre outras ações. Contudo, como afirma Isabel Solé (1998), é especialmente o ensino das estratégias de leitura que pode ajudar "o 
estudante a aplicar seu conhecimento prévio, a realizar inferências para interpretar o texto e a identificar e esclarecer o que não entende". Dessa maneira, compreendemos que são sobretudo as estratégias e o desenvolvimento do hábito de ler e do gosto pela leitura ${ }^{1}$ que possibilitarão ao leitor adquirir e desenvolver habilidades, capacidades de aprender cada vez mais, contribuindo para a melhoria de sua proficiência em leitura. Ademais, melhorando a capacidade de leitura, o aluno amplia as suas interações com os textos, compreendendo melhor os seus significados. Assim, formar o leitor, desde a tenra idade, não se resume a ensiná-lo a "codificar e decodificar símbolos", mas envolve a compreensão da leitura e da escrita como práticas sociais.

É nesse sentido, que tem sido frequentemente evocado o conceito de letramento. Magda Soares (1998, p. 47) conceitua letramento como "estado ou condição de quem não apenas sabe ler e escrever, mas cultiva e exerce as práticas sociais que usam a escrita e a leitura". Dentre essas práticas de leitura e escrita merecem destaque aquelas que se referem aos textos literários. Daí a possibilidade de nos referirmos a um tipo de letramento específico: o letramento literário. $O$ letramento literário tem sido definido como sendo o estado ou condição de quem não apenas é capaz de ler um texto, mas dele se apropria, deixando a condição de simples "espectador" passivo para a condição de leitor literário ou mais precisamente "[...] o processo de apropriação da literatura enquanto construção literária de sentidos" (PAULINO \& COSSON, 2009, p. 67). Nessa definição, é importante destacar que o letramento literário não é apenas uma habilidade pronta e acabada de ler textos literários, visto que exige uma atualização constante do leitor em relação ao mundo literário. É nessa questão que pontuamos os problemas nas instituições de ensino, uma vez que em sua maioria elas parecem não conseguir utilizar a capacidade que a literatura tem de incentivar o aluno a ser um leitor frequente e contumaz. A leitura literária, quando realizada adequadamente poderá se transformar no início de uma longa e prazerosa caminhada para outras leituras. É na escola que essa caminhada poderia tomar um rumo que reforçasse o(s) letramento(s) para que os alunos pudessem, entre outras coisas, se tornarem aptos a apreender o conteúdo de ensino e transformá-lo em competências linguísticas e outras.

1 Uma discussão sobre hábito de leitura e gosto pela leitura é feita em Corrêa (2012). 
Diversos autores têm indicado que o letramento literário deve ser feito a partir da construção do gosto do aluno pela literatura (COSSON, 2006; PAULINO, 2001). O aluno deve se sentir próximo da literatura para que essa faça parte de sua vida e o ajude a desenvolver suas capacidades de escrita. Isso só é possível a partir do incentivo à cultura da leitura literária e isso certamente pode ser feito de diversas maneiras.

Dentre as diversas possibilidades de se trabalhar com o letramento literário e desenvolver o gosto e o prazer pela leitura, situam-se as práticas pedagógicas desenvolvidas no âmbito das bibliotecas escolares. Algumas até envolvem as estratégias de leitura divulgadas por Solé (1998) e Girotto e Souza (2010), procedimentos que aliam o texto literário, ao espaço da biblioteca escolar como espaço mediador de leitura.

\section{LETRAMENTO LITERÁRIO, BIBLIOTECAS ESCOLARES E MEDIAÇÕES DE LEITURAS}

Escola e literatura sempre estiveram relacionadas e "o acesso aos bens culturais, proporcionado por uma educação democrática, pode muitas vezes significar o acesso aos veículos onde esses bens se encontram registrados - entre eles, o livro", conforme aponta Ezequiel Theodoro da Silva (2005, p. 31-32). A escola acaba assumindo a responsabilidade de democratizar o acesso ao livro e à leitura, por ser um espaço de circulação de conhecimentos e de ampliação cultural, onde se ensina a ler e a escrever e onde a literatura tem lugar neste processo educativo. Pela leitura, o indivíduo pode integrar-se à sociedade, participando ativamente dela. Dessa forma, "a conquista da habilidade de ler é o primeiro passo para a assimilação dos valores da sociedade" (ZILBERMAN, 1982, p. 16).

O letramento literário tem contemplado trabalhos relevantes de pesquisa, tais como: o processo de escolarização da literatura; as práticas de formação de leitores; as especificidades da leitura do texto literário, as estratégias metacognitivas de compreensão da leitura, dentre outros. Uma parcela dos estudos e pesquisas tem estado restrito, hoje, à esfera escolar. Isso se confirma pelo fato de ser a escola a grande promotora da leitura literária. E cabe mesmo a ela a tarefa de apresentar a 
literatura aos alunos, sobretudo num país no qual o acesso ao livro e à cultura é ainda bastante dificultado.

A pesquisa Retratos da leitura no Brasil aponta que se amplia o número de leitores à medida que cresce a escolaridade dos brasileiros. A investigação também traz questionamentos relacionados aos tipos de leituras que se faz e ressalta que a leitura cultural ainda é muito pequena em qualquer nível de escolaridade. Ainda de acordo com essa pesquisa, Galeno Amorim (2010) ressalta que a média de leitura do país é de 4,7 livros lidos per capita/ano; e deste total, 3,4 livros são de indicações da escola e 1,3 livros foram lidos fora do ambiente escolar. Diante desses dados podemos deduzir que apesar dos baixos índices indicados é ainda por meio da escola que há um aumento de leitores. Nesse sentido, a biblioteca escolar constitui um espaço privilegiado em que os estudantes poderão ter acesso e conviver com os livros. Em muitos casos, ela constitui o único local de acesso a esse suporte, tendo em vista a precariedade econômica e social dos estudantes.

Para Motta (1999, p. 21), a biblioteca escolar é um local da instituição "que deve estar bem definida quanto à sua organização e funcionamento para que venha facilitar o ensino", e é imprescindível ser um lugar bem gerenciado, organizado e prazeroso. A biblioteca escolar deveria ser um espaço diferente dos outros ambientes educativos da escola, pois deveria promover práticas de leituras, interação entre o aluno, professor, bibliotecário e auxiliares, vinculadas a uma variada gama de informações e aprendizagens.

Para Aguiar (1994), o caráter social da biblioteca é um aspecto importante, pois é preciso ter "condições de acesso à leitura, ofertadas às diferentes camadas da população" (AGUIAR, 1994, p. 99). Para a autora, é preciso que a biblioteca esteja aliada a uma mudança social para que todos tenham acesso à informação e saibam utilizá-la. De acordo com o Plano Nacional do Livro e Leitura - PNLL, as bibliotecas não podem ser mais concebidas como depósitos de livros, mas como difusoras de "informação e cultura, centro de educação continuada, núcleo de lazer e entretenimento, estimulando a criação e a fruição dos mais diversificados bens artístico-culturais" (MARQUES NETO, 2010, p. 46). São espaços dotados de funções de grande responsabilidade e que se bem aproveitados podem mudar a realidade da comunidade escolar. De acordo com Edmir Perrotti (1990), especialista em estudos sobre leitura no país, a biblioteca precisa ter outra finalidade que não 
seja simplesmente a de um "depósito de livros", é preciso uma articulação para não se tratar de unidade isolada. Perrotti (1990) reforça a ideia de formar redes, um conjunto de espaços, dos quais o pesquisador denomina de "estações de conhecimento", cujo objetivo é a apropriação do saber dos sujeitos envolvidos.

Diante do exposto, a biblioteca escolar tem função educativa, ao mostrar para o aluno a diversidade de saberes e de pontos de vista, além dos múltiplos esforços em compreender o mundo. Dessa forma, a biblioteca pode se converter num mecanismo de transformação das relações entre alunos, professores, bibliotecários e auxiliares, entre outros, proporcionando mediações e favorecendo o ganho da autonomia e envolvimento de todos com a leitura.

No entanto, a realidade brasileira é outra. Waldeck Carneiro da Silva (1995, p. 24-25) expõe:

[...] quando existe biblioteca, esses espaços geralmente não passam de depósitos de livros e de outros objetos, com horários de funcionamento breves e irregulares, ou ainda são convertidas em espaços de punição (onde os alunos ficam de castigo para copiar trechos de enciclopédias porque se comportaram de modo inadequado em outros espaços escolares), cujos atendentes são professores aposentados ou readaptados, enfadados da sala de aula e de alunos.

Para o autor essa situação torna-se agravante quando se pensa que a biblioteca escolar é para a maior parte das crianças brasileiras o primeiro (ou único) local de contato com o livro. Ele lembra que as bibliotecas escolares sofrem com problemas de ordem "extra bibliotecas" (como desvalorização social da leitura, escassez de políticas públicas) e "intra bibliotecas" (inadequações no espaço, acervo sem diversidade nem qualidade, sistema de classificação ininteligível, regulamentos muito rígidos, horários inflexíveis, preocupação excessiva com silêncio, arrumação e disciplina, bibliotecários mal preparados, entre outros).

Apontados alguns aspectos relacionados à biblioteca escolar, questionamos: Como a biblioteca da escola poderia se tornar um ambiente privilegiado para a construção de práticas pedagógicas/educativas relevantes para mediação de leitura (especialmente, a leitura literária)?

Discute-se muito sobre o papel da leitura nas escolas, porém as atividades e objetivos nem sempre estão definidos no ambiente escolar. Ezequiel Theodoro da Silva (2005) explica que é preciso que a escola saiba qual o objetivo da leitura em 
seu âmbito; que planeje as ações a serem desenvolvidas durante o ano letivo e que, ano a ano, incorpore as experiências bem-sucedidas em detrimento daquelas que não obtiveram o sucesso desejado. Faremos menção à mediação da leitura na escola com enfoque no texto de literatura. A respeito desse domínio de textos, Rovilson J. Silva afirma que "[...] exigirá um professor mediador que conheça os meandros para se formar leitor e, ao mesmo tempo, não ignore de modo geral o conceito de texto artístico, a especificidade do texto literário, a função da literatura" (2009, p. 172) De acordo com Girotto e Souza (2010), mediadores de leitura são "sujeitos que leem, discutem, promovem e facilitam o diálogo entre texto e leitor" ( $p$. 19). O mediador é alguém que avalia e seleciona estratégias, que organiza, interpreta e elabora as experiências. Num ambiente de troca/interação, o mediador provoca curiosidade, mostra envolvimento e interesse, estimula a significação, a abstração e a reflexão, promove o compartilhamento e o respeito aos diversos pontos de vista, incentiva a mudança e a participação ativa. Assim, precisamos entender que a leitura e sua mediação é um processo cultural, portanto, "não pode ignorar a importância de uma biblioteca aberta, interativa, espaço livre para a expressão genuína da criança e do jovem." (CARVALHO, 2002, p. 23).

Segundo Silva e Scorsi (2009), a "biblioteca deve ser um espaço de diálogo, liberdade, descoberta, e não um lugar de acumulação e ordenação de livros". As pesquisadoras apontam também que o mediador precisa de um bom repertório de leituras para ter condições de fazer uma seleção adequada de textos. É preciso reforçar o envolvimento da comunidade escolar (direção, supervisão, professores, alunos, pais, bibliotecários e auxiliares), pois todos são responsáveis para a formação de leitores.

Em relação à mediação literária é perceptível que cabe à escola oferecer os textos de literatura, porque ela "[...] se apresenta como potencial polo disseminador de uma cultura literária, rompendo seus limites e contribuindo em parte para o alargamento social da leitura." (MARTINS, 2008, p. 17). Diante das várias concepções de literatura, destaca-se também o caráter sociológico que a literatura possui. Para Carvalho (2001, p. 56 apud GOMES e BORTOLIN, 2011) ela "é tomada enquanto manifestação cultural de diferentes estratos sociais, particularizando-se pelos seus valores e ideologias, o que por sua vez determina o modo de produção e circulação de seus produtos culturais". Para acontecer de fato uma mediação que 
contribua com a formação do leitor literário na escola, Soares (2010, p. 12) defende que:

\begin{abstract}
Se a formação do leitor literário requer, para além do contato espontâneo com os textos, mediação segura, capaz de fazer intervenções que favoreçam a articulação dos horizontes envolvidos nas experiências de leituras literárias, temos que indagar, necessariamente, pelas concepções acerca de literatura e ensino dos docentes a quem foram endereçadas essas sugestões de práticas, sem o que elas podem resvalar para uma mera imposição metodológica, em detrimentos dos saberes e fazeres docentes.
\end{abstract}

Assim, é possível afirmar que a leitura literária exige uma ação conjunta de todos os agentes envolvidos: família, escola, leitores e profissionais, para chamar a atenção dos educandos quanto a sua importância.

É a partir informação e por acreditarmos que formar leitores literários deveria ser uma função de toda a escola é que propomos, neste artigo, pesquisar a circulação dos livros do PNBE, bem como as atividades de mediação de leitura das bibliotecas escolares da cidade de Ouro Preto, Minas Gerais. Sobre a metodologia da pesquisa, explicaremos a seguir.

\title{
5 O CONTEXTO E ALGUNS RESULTADOS
}

O município de Ouro Preto localiza-se a $96 \mathrm{~km}^{2}$ de Belo Horizonte, capital do estado de Minas Gerais, com uma população estimada em 2015 em 74.036 habitantes. Atualmente possui 12 distritos: Amarantina, Antônio Pereira, Cachoeira do Campo, Engenheiro Correia, Glaura (Casa Branca), Lavras Novas, Miguel Burnier, Rodrigo Silva, Santa Rita, Santo Antônio do Leite, Santo Antônio do Salto e São Bartolomeu.

O município tem origem no arraial do Padre Faria fundado por volta de 1698, elevado à categoria de vila em 1711 - Vila Rica, escolhida como capital da nova capitania de Minas Gerais em 1720. Recebeu em 1823 o título de Cidade Imperial, passando a ser denominada Imperial Cidade de Ouro Preto e se tornando a capital da então província das Minas Gerais e, mais tarde, do estado de Minas Gerais. Foi

2 Informações encontradas na página da Prefeitura Municipal de Ouro Preto-MG, por meio do link: http://www.ouropreto.mg.gov.br/localizacao. Acesso em 10 de novembro de 2016. 
elevada a Patrimônio Nacional em 1933, sendo tombada cinco anos depois, e declarada, em 1980, Patrimônio Cultural da Humanidade.

Ouro Preto possui cinquenta e uma instituições escolares, sendo dezesseis creches, cinco escolas municipais de Educação Infantil e trinta escolas que atendem o Ensino Fundamental. Todas as creches municipais recebem o berçário 1 e 2 e o maternal. Das cinco escolas municipais de Educação Infantil, quatro acolhem o maternal e o $1^{\circ}$ e $2^{\circ}$ períodos, e uma atende o berçário 1 e 2 , maternal e $1^{\circ}$ e $2^{\circ}$ períodos. Das escolas que recebem o Ensino Fundamental, apenas quatro não atendem a Educação Infantil e apenas uma não atende $01^{\circ}$ ano do Ensino Fundamental. As 30 escolas que acolhem o Ensino Fundamental estão assim localizadas:

Quadro 1 - Relação de escolas do município de Ouro Preto - MG

\begin{tabular}{|c|c|c|}
\hline & INSTITUIÇÕES & $\begin{array}{l}\text { SEGMENTOS E NÍVEIS } \\
\text { OFERTADOS }\end{array}$ \\
\hline 1 & E. M. Aleijadinho - Santo Antônio do Salto & $\begin{array}{l}\text { Educação Infantil (Maternal) ao 9o } \\
\text { ano do Ensino Fundamental }\end{array}$ \\
\hline 2 & E. M. Alfredo Baeta - Ouro Preto & $\begin{array}{l}\text { Educação Infantil (Maternal) ao } 5^{\circ} \\
\text { ano do Ensino Fundamental }\end{array}$ \\
\hline 3 & E. M. Ana Pereira de Lima - Amarantina & $\begin{array}{l}1^{\circ}, 4^{\circ} \text { e } 5^{\circ} \text { ano do Ensino } \\
\text { Fundamental }\end{array}$ \\
\hline 4 & E. M. Benedito Xavier - Glaura & $\begin{array}{l}\text { Educação Infantil (Maternal) ao 90 } \\
\text { ano do Ensino Fundamental }\end{array}$ \\
\hline 5 & E. M. Dr. Alves de Brito - Ouro Preto & $\begin{array}{l}\text { Educação Infantil (Maternal) ao 90 } \\
\text { ano do Ensino Fundamental }\end{array}$ \\
\hline 6 & E. M. Dr. Pedrosa - Santo Antônio do Leite & $\begin{array}{l}\text { Educação Infantil (10 Período) ao 9o } \\
\text { ano do Ensino Fundamental }\end{array}$ \\
\hline 7 & E. M. Inácio de Souza - Santa Rita & $\begin{array}{l}\text { Educação Infantil (Maternal), } 1^{\circ} \text { ao } 5^{\circ} \\
\text { ano do Ensino Fundamental }\end{array}$ \\
\hline 8 & E. M. Izaura Mendes - Ouro Preto & $1^{\circ}$ ao 9음 ano do Ensino Fundamental \\
\hline 9 & E. M. José Estevam Braga - Engenheiro Correia & $\begin{array}{l}\text { Educação Infantil (Maternal) ao } 5^{\circ} \\
\text { ano do Ensino Fundamental }\end{array}$ \\
\hline 10 & E. M. Lavras Novas - Lavras Novas & $\begin{array}{l}\text { Educação Infantil (Maternal) ao 9o } \\
\text { ano do Ensino Fundamental }\end{array}$ \\
\hline 11 & E. M. Major Raimundo Felicíssimo - Amarantina & $\begin{array}{l}\text { Educação Infantil (10 Período) ao 9o } \\
\text { ano do Ensino Fundamental }\end{array}$ \\
\hline 12 & $\begin{array}{l}\text { E. M. Maria Leandra Rodrigues de Oliveira - Santa } \\
\text { Rita }\end{array}$ & $\begin{array}{l}\text { Educação Infantil (10 Período) ao 50 } \\
\text { ano do Ensino Fundamental }\end{array}$ \\
\hline 13 & E. M. Monsenhor João Castilho Barbosa - Ouro Preto & $\begin{array}{l}\text { Educação Infantil (10 Período) ao 9º } \\
\text { ano do Ensino Fundamental }\end{array}$ \\
\hline 14 & E. M. Monsenhor Rafael - Miguel Burnier & $\begin{array}{l}\text { Educação Infantil (Maternal) ao } 9^{\circ} \\
\text { ano do Ensino Fundamental }\end{array}$ \\
\hline 15 & E. M. Nossa Senhora das Graças - Ouro Preto & $\begin{array}{l}\text { Educação Infantil (Maternal) ao 50 } \\
\text { ano do Ensino Fundamental }\end{array}$ \\
\hline 16 & E. M. Padre Antônio Pedrosa - Ouro Peto & $\begin{array}{l}\text { Educação Infantil (Maternal, } 1^{\circ} \text { e e } 2^{\circ} \\
\text { Períodos), } 2^{\circ} \text { e } 3^{\circ} \text { ano do Ensino }\end{array}$ \\
\hline
\end{tabular}




\begin{tabular}{|c|c|c|}
\hline & & Fundamental \\
\hline 17 & E. M. Padre Carmélio Augusto Teixeira - Ouro Preto & $\begin{array}{l}\text { Educação Infantil (Maternal) ao 9ำ } \\
\text { ano do Ensino Fundamental }\end{array}$ \\
\hline 18 & E. M. Padre Martins - Santa Rita & $\begin{array}{l}\text { Educação Infantil (1ํ Período), } 1^{\circ} \text { ao } \\
5^{\circ} \text { ano do Ensino Fundamental }\end{array}$ \\
\hline 19 & E. M. Prof. Washington Andrade - Santa Rita & $\begin{array}{l}\text { Educação Infantil (1ํ Período), } 1^{\circ} \text { ao } \\
5^{\circ} \text { ano do Ensino Fundamental }\end{array}$ \\
\hline 20 & E. M. Profa. Celina Cruz - Miguel Burnier & $\begin{array}{l}\text { Educação Infantil (Maternal) ao 5ำ } \\
\text { ano do Ensino Fundamental }\end{array}$ \\
\hline 21 & $\begin{array}{l}\text { E. M. Prof. Haydêe Antunes (CAIC) - Cachoeira do } \\
\text { Campo }\end{array}$ & $1^{\circ}$ ao $9^{\circ}$ ano do Ensino Fundamental \\
\hline 22 & E. M. Profa. Juventina Drummond - Ouro Preto & $1^{\circ}$ ao $9^{\circ}$ ano do Ensino Fundamental \\
\hline 23 & E. M. Prof. Adhalmir Santos Maia - Ouro Preto & $\begin{array}{l}\text { Educação Infantil (Maternal) ao 5ำ } \\
\text { ano do Ensino Fundamental }\end{array}$ \\
\hline 24 & E. M. Prof. Francisco Pignataro - Ouro Preto & 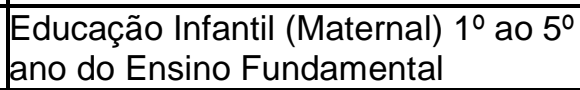 \\
\hline 25 & E. M. Prof. Hélio Homem de Faria - Ouro Preto & $\begin{array}{l}\text { Educação Infantil (Maternal) ao 5ำ } \\
\text { ano do Ensino Fundamental }\end{array}$ \\
\hline 26 & E. M. René Gianetti - Ouro Preto & $\begin{array}{l}\text { Educação Infantil (Maternal) ao 5ำ } \\
\text { ano do Ensino Fundamental }\end{array}$ \\
\hline 27 & E. M. São Sebastião - Ouro Preto & $\begin{array}{l}\text { Educação Infantil (1ํo período) ao 5을 } \\
\text { ano do Ensino Fundamental }\end{array}$ \\
\hline 28 & E.M. Simão Lacerda - Ouro Preto & $\begin{array}{l}\text { Educação Infantil (1ํ Período) ao } 5^{\circ} \\
\text { ano do Ensino Fundamental }\end{array}$ \\
\hline 29 & E. M. Tomás Antônio Gonzaga - Ouro Preto & $\begin{array}{l}\text { Educação Infantil (1ํ Período) ao 9ำ } \\
\text { ano do Ensino Fundamental }\end{array}$ \\
\hline 30 & E. M. Washington de Araújo Dias - Ouro Preto & $\begin{array}{l}\text { Educação Infantil (1ํ Período) ao } 2^{\circ} \\
\text { ano do Ensino Fundamental }\end{array}$ \\
\hline
\end{tabular}

Fonte: Prefeitura Municipal de Ouro Preto - MG/(Secretaria de Educação) - adaptado

Com o propósito de realizar um estudo sobre a ampliação e a circulação dos acervos do PNBE nas escolas públicas municipais de Ouro Preto, visando à formação do leitor e o letramento literário, preparamos uma entrevista, a ser respondida por um responsável da escola. A entrevista foi pontual e quis saber:
a) Os acervos do PNBE chegaram à escola?
b) Quem recebeu esses acervos na escola?
c) Para onde foram encaminhados os livros?
d) Que usos têm sido feitos desses livros?
e) As professoras usam os livros? De que maneira?
f) Os alunos usam os livros? Como os alunos utilizam os livros (levam pra casa, leem na sala, leem na biblioteca, leem em outros momentos e espaço)?
g) Outras pessoas usam esses livros? Quem? Como? 
Os dados foram coletados no final do mês de outubro de 2016, por meio de contato direto com gestores das escolas. Todas as 30 escolas do município de Ouro Preto que ofertam os anos iniciais do Ensino Fundamental foram contatadas. Dessas 30 escolas, 22 escolas participaram da entrevista, sendo que nosso contato com as outras cinco instituições escolares não obteve sucesso, pois não conseguimos conversar diretamente com o gestor escolar. Sobre as 22 escolas terem ou não recebido os acervos do PNBE, obtivemos as seguintes respostas:

\section{Gráfico 1 - Recebimento dos acervos do PNBE nas escolas de Ouro Preto}

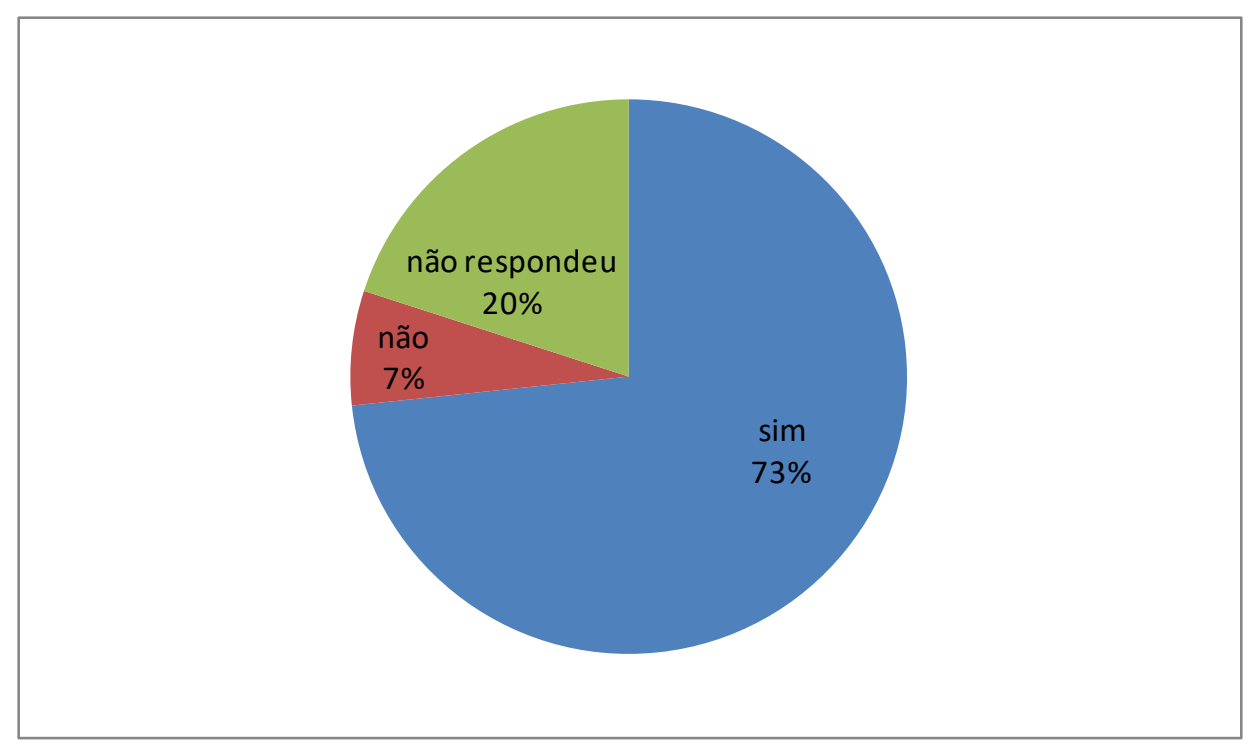

Fonte: os autores

Verifica-se que cerca de $7 \%$ das escolas declararam não ter recebido os livros, no entanto, os acervos do PNBE são distribuídos pelos Correios e todas as escolas brasileiras deveriam ter recebido. A pergunta não foi respondida por $20 \%$ dos entrevistados, infere-se que o gestor ou não sabia sobre os livros e a destinação dos acervos, ou não respondeu por desconhecer o Programa (PNBE). 
Gráfico 2 - Responsáveis pelo recebimento dos acervos do PNBE nas escolas

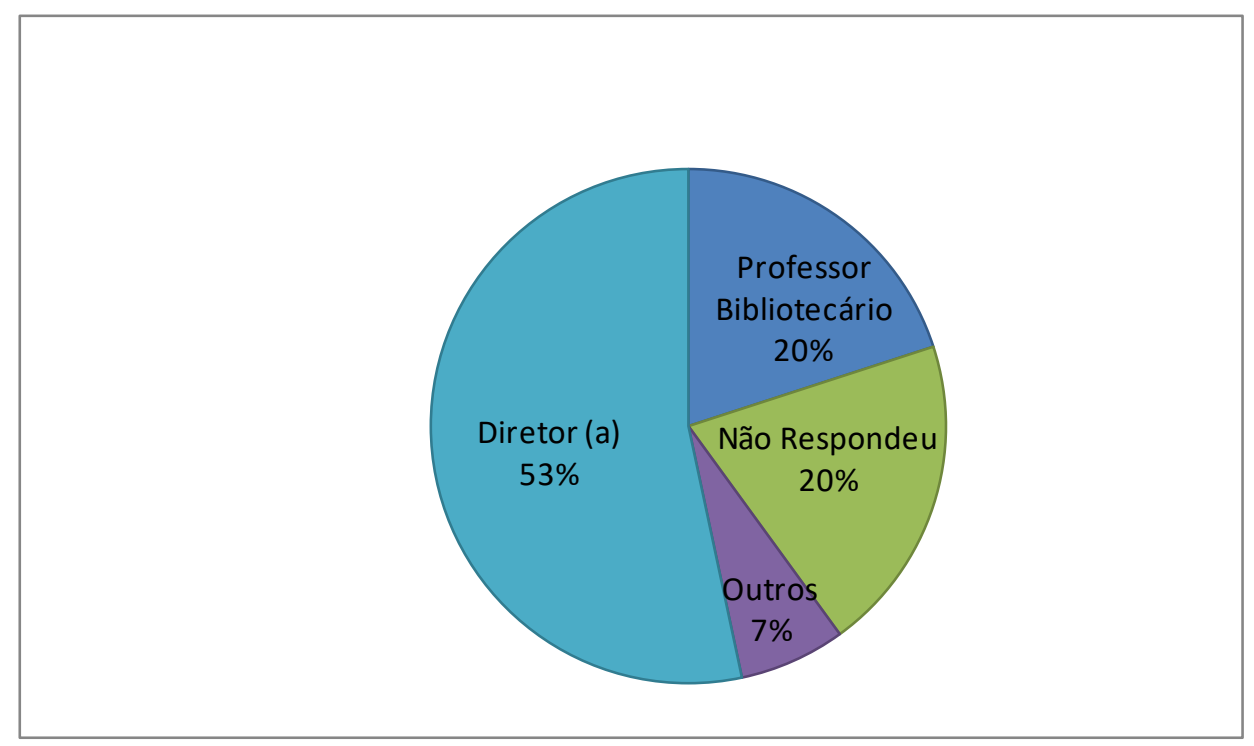

Fonte: os autores

O professor bibliotecário é um docente que se encontra em desvio de função, professor afastado de sala de aula por motivos de doença ou laudo médico (quadros de distúrbios emocionais, estresse e similares). A função de bibliotecário nas escolas de educação básica ainda é vista como uma função que não exige formação específica, o que contraria a legislação vigente, inclusive a Lei Federal 12.244 de 2010. Delegam-se a professores, muitas vezes afastados da sala de aula pelos motivos acima citados, a ida para a biblioteca da escola. Neste caso, 20\% das entrevistas apontam que eles são os responsáveis por receber o acervo. Decisão muito bem tomada se pensarmos que será ele depois quem vai cadastrar os livros no acervo da escola e utilizar tais livros para atividades de contextualização da leitura e motivação para o ato de ler.

É de extrema importância o papel do professor bibliotecário na mediação da leitura, pois é neles que os alunos vão encontrar o incentivo para utilizar o acervo e frequentar a biblioteca.

[...] o professor é encarregado compulsoriamente de aproximar o educando da leitura; porém, é fundamental que ele faça essa mediação, mostrando o texto como algo prazeroso e não como instrumento de avaliação e tarefa. [...] E assim o leitor, além de se cumpliciar com o autor e os personagens, tem no professor também um cúmplice; isto é, se o professor estiver 
disposto a compartilhar com ele a leitura/as leituras (BORTOLIN, 2001, p. 34).

Outro contexto favorável foi que $53 \%$ dos entrevistados declaram ter sido o diretor quem recebeu os livros. Se partirmos do pressuposto de que o diretor é um gestor responsável pela articulação entre os vários setores, para promover a participação de toda comunidade escolar nos processos de ensino-aprendizagem (VAZ, 2016), isto é bastante positivo.

Tanto diretores escolares como professores bibliotecários ao receberem os acervos distribuídos pelo correio deveriam tornar público tal recebimento, divulgar com todo o corpo docente da escola que os livros infantis haviam chegado e estariam disponíveis para leitura e utilização em sala de aula, afinal:

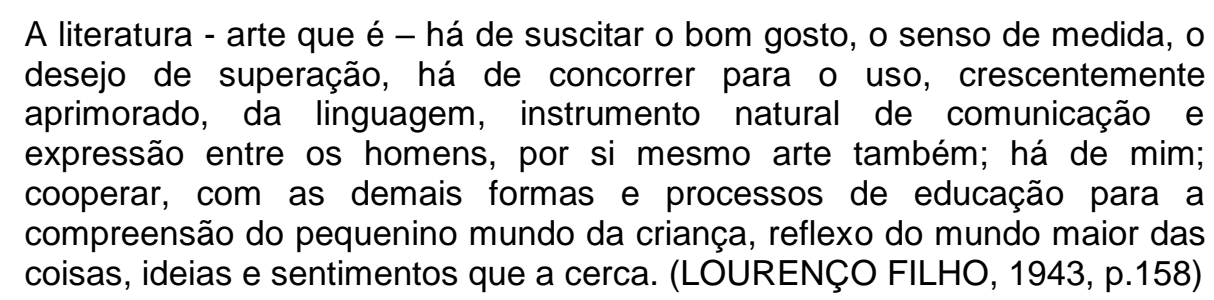

Vejamos então, se os livros, a partir do momento em que chegaram às escolas públicas de Ouro Preto, foram utilizados.

Gráfico 3 - Local de guarda e usos dos livros do acervo do PNBE nas escolas

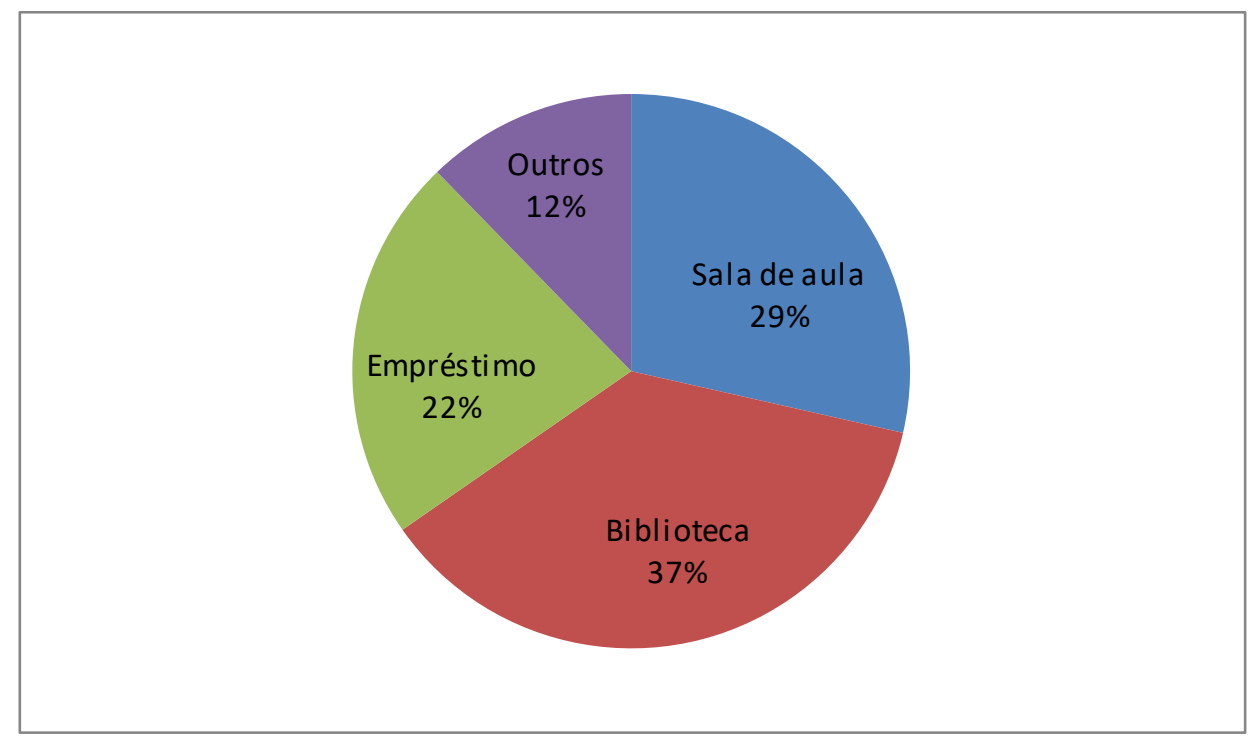

Fonte: os autores 
O gráfico 3 revela onde os livros distribuídos pelo MEC foram colocados e de certa maneira como estão sendo utilizados. Se verificarmos que cerca de $37 \%$ dos respondentes afirmaram que os livros infantis estão na biblioteca e que $22 \%$ responderam que tais exemplares são utilizados para empréstimo, não podemos excluir então que os empréstimos são feitos na biblioteca escolar e, portanto, 59\% do acervo é colocado à disposição dos alunos para leitura, seja no espaço da escola, seja fora, nos lares dos alunos.

Aguiar (2006) traz concepções que compreendem o espaço da biblioteca na escola como uma "agência social da comunicação da cultura", podendo encontrar na organização do sistema escolar fatores determinantes para seu desenvolvimento ou atraso. A biblioteca não deve ser um espaço fechado, onde os livros são guardados, pois ela abriga ainda outros produtos culturais como materiais informativos e de lazer, revistas, catálogos, mapas, filmes, músicas, jogos; é local de criação e comunicação de ideias e está em constante intercâmbio com a sala de aula. A ela atribuímos a formação de leitores e, para tanto, o acervo deve estar adequado ao público jovem, seus interesses e necessidades, não apenas em relação à informação mas também ao lazer. A organização do espaço e a classificação dos livros e outros materiais, deve oferecer facilidade de manuseio, condições de pesquisa e fruição das obras literárias uma vez que os livros devem ser considerados "[...] objetos de consumo, passíveis de serem substituídos nas estantes" (AGUIAR, 2006, p.259).

Algumas escolas, no entanto, declararam não emprestar os livros infantis, afirmando que "os alunos não devolvem", "as crianças estragam". Assim, diante dessas respostas, percebemos que algumas instituições pesquisadas são espaços fechados, no sentido literal. Muitos alunos não têm acesso ao espaço da biblioteca escolar quando não estão acompanhados por docentes. Os bibliotecários ou responsáveis pelos materiais de leitura muitas vezes se sentem donos dos livros e não permitem a retirada, o empréstimo, ou até mesmo que os professores retirem livros para levarem para suas salas de aula.

Quanto a 29\% das escolas pesquisadas dizerem que os livros infantis estão na sala de aula, muitas vezes o professor monta um canto ou uma caixa de leitura. Segundo Cerrillo (2003), o canto da leitura deve preferencialmente ser organizado pelo professor juntamente com os alunos, de forma que possa satisfazer as 
necessidades informativas pontuais da sala, contemplando a série, considerando o número de alunos da classe e, embora em pequeno número, os materiais selecionados para compor os cantos devem oferecer variedade e qualidade.

Ainda para o autor (CERRILLO, 2003), os projetos pedagógicos de aprendizagem de leitura devem ser desenvolvidos por meio de uma política de leitura voltada para o letramento, onde as crianças devem aprender a ler produzindo atividades a partir de leituras do meio social. A função do canto da leitura é oferecer aos alunos possibilidade de contato e observação dos variados textos produzidos atualmente, como a história em quadrinhos, a poesia, parlendas e tantos outros portadores, de modo que cada aluno utilize seu saber diante do contato com esses materiais escritos. A leitura oferece uma atividade de confronto entre o saber produzido, com o conhecimento interior e com os problemas atuais do mundo. Aprender a ler é ser leitor, e ser leitor é conhecer e compreender o funcionamento da produção escrita na sociedade em que vivemos. O projeto pedagógico do cantinho de leitura, portanto, busca integrar esse recurso (formado de escritos que não são livros escolares) às práticas cotidianas da sala de aula, e, como tal, constitui-se como mais um espaço de mediação de leitura à disposição do professor e da escola.

Quando os respondentes de Ouro Preto nos dizem que 29\% do acervo do PNBE encontra-se nas salas de aula, inferimos que essas salas têm certa quantidade de livros literários. Dessa forma, gostaríamos de saber como tais textos são utilizados no momento da leitura. Assim, o próximo gráfico aborda as leituras literárias de tais livros infantis. 
Gráfico 4 - Leituras literárias dos acervos do PNBE nas escolas

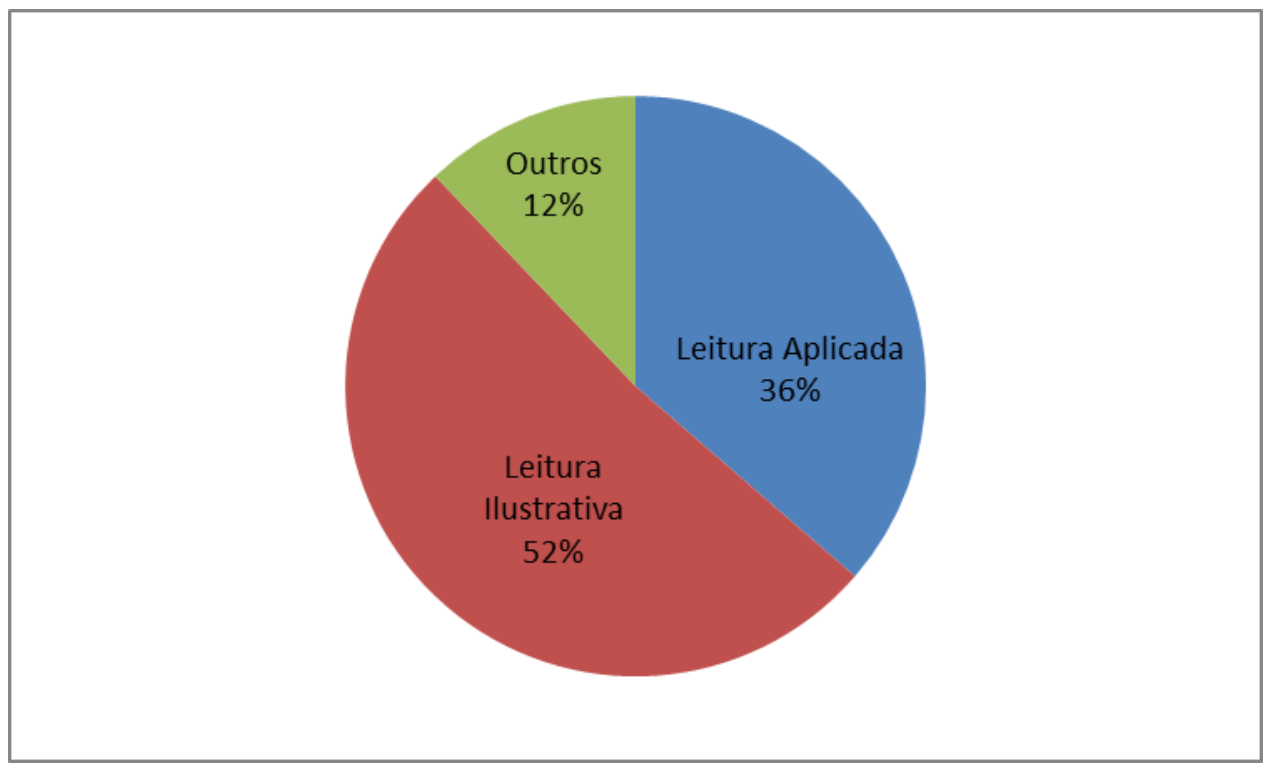

Fonte: os autores

Os dados acima foram inferidos a partir das respostas dadas pelos entrevistados, não tendo sido apresentados diretamente como "leitura aplicada" ou "leitura ilustrativa", termos utilizados a partir do artigo de Cosson (2015).

Para Cosson (2015), a leitura aplicada é aquela da promoção do conhecimento, destinada ao aprendizado de alguma coisa, do qual o texto literário é o veículo. Poderíamos exemplificar aqui professores que, ao pedir a leitura de determinado texto, segue pedindo o preenchimento de uma ficha de leitura, ou distribui atividades de ortografia e gramática para que os alunos apliquem uma regra no texto.

O mesmo autor (2015) define como leitura ilustrativa aquela que está a serviço da fruição, voltada para a inserção do aluno/leitor no mundo da escrita. Esse tipo de leitura é capaz de ampliar o conhecimento prévio do estudante, bem como fomentar a vontade de ler um livro.

Quanto às escolas de Ouro Preto, 52\% responderam que os livros infantis do PNBE estão sendo utilizados em momentos de leitura ilustrativa. Tal dado evidencia o espaço da sala de aula como aquele que tem sido utilizado de maneira que haja um estímulo à leitura. Assim, o cantinho da leitura pode ser um espaço que contribuirá na mediação da leitura, na formação de leitores autônomos e crítico, pois a escola, a partir da figura do professor, deve, segundo Burlamaque (2006) começar: 
(...) a resgatar a dimensão lúdica e prazerosa da leitura, através de diferentes modalidades e da diversidade dos gêneros e suportes multimídias, passando a apresentar formas criativas de promoção da leitura - a criação ou dinamização de bibliotecas e salas de leitura nas escolas - ela estará incorporando enfim, a leitura como prática social. (BURLAMAQUE, 2006, p.85)

Neste sentido, o professor é capaz de preparar seu aluno para práticas leitoras também emancipatórias como possibilidades reais de intervenção e que permitam o verdadeiro encontro da criança com a leitura "prazer", com a leitura "sentidos", com a leitura que "favoreça a compreensão da realidade".

Gráfico 5 - O uso dos livros dos acervos do PNBE na perspectiva docente

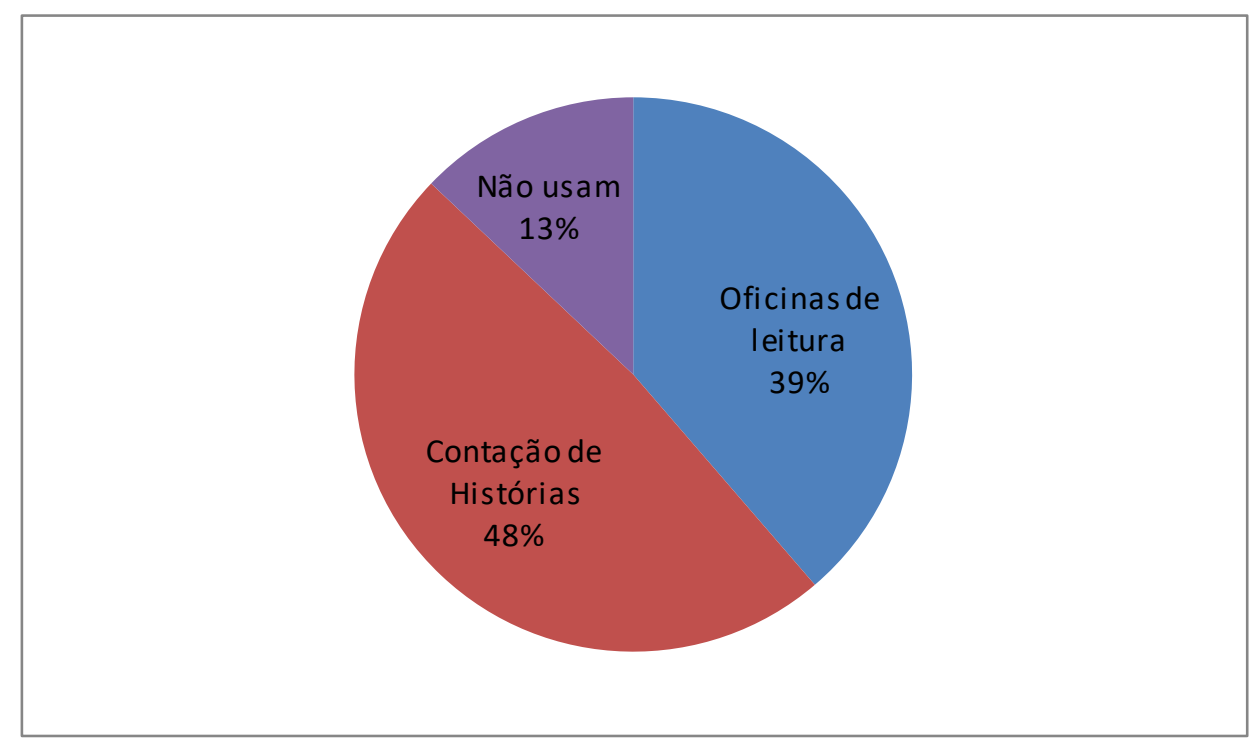

Fonte: os autores

Além daquelas $52 \%$ de instituições escolares que propõem a leitura ilustrativa, quando perguntamos sobre os usos dos livros do PNBE para os professores, os respondentes elencaram uma atividade bastante conhecida que é o momento de contação de histórias. Assim, os livros do acervo do PNBE são utilizados nas contações de $48 \%$ das escolas.

Sobre isso devemos lembrar que quando o professor conta uma história ele não está trabalhando com a leitura e sim lendo em voz alta ou fazendo uma performance a partir de um livro infantil, para seus alunos, que naquele momento são ouvintes. É claro que não podemos negar que 
Quando alguém narra uma história, ela não é apenas ouvida, "absorvida" por aquele que a ouve; há entre ouvinte e contador uma interação que promove a reelaboração da história: quem ouve completa a história da sua própria forma, com base em suas experiências; e quem conta também dá forma ao seu contar a partir do encontro subjetivo com o ouvinte. Como afirma Egan, as histórias têm um significado afetivo: "um bom contador de histórias faz vibrar as emoções, tal como um bom violinista faz vibrar as cordas de um violino (1994, p.41)." (UMBELINO, 2005, p.25)

As chamadas oficinas de leitura, citadas por 39\% dos respondentes, dizem respeito a atividades de leituras diversas em sala de aula. $O$ ato de ler é um dos processos pelos quais acontece a interação entre os seres humanos. Além de promover a reflexão sobre diferentes assuntos, a leitura favorece também a formação do sujeito crítico. Essas oficinas permitem as múltiplas abordagens, utilizando-se a leitura como processo de conhecimento e compreensão de textos. Os Parâmetros Curriculares Nacionais (PCN) já apontavam para isso:

\footnotetext{
A leitura é o processo no qual o leitor realiza um trabalho ativo de compreensão e interpretação do texto, a partir de seus objetivos, de seu conhecimento sobre o assunto, sobre o autor, de tudo o que se sabe sobre linguagem, etc. [...] Trata-se de uma atividade que implica estratégias de seleção, antecipação, inferência e verificação, sem as quais não é possível proficiência [...] (BRASIL, 1998, p.69).
}

Resta-nos saber se realmente as oficinas de leitura citadas estão garantindo um trabalho efetivo de formação de leitores, competentes e críticos, capazes de realizar tarefas como as citadas acima - de seleção, antecipação, inferência, verificação, estabelecimento de relações, dentre outras -, muito além da decodificação e da localização de informações num texto.

\section{CONSIDERAÇÕES FINAIS}

A leitura, conforme já aludimos, é uma importante ferramenta no processo de aprendizagem do aluno e por sua formação social. Entendemos que a "leitura gera conhecimento", cabendo à escola oferecer objetos culturais além daqueles do cotidiano, da cultura de massa, a fim de não se submeter à lógica da literatura como entretenimento descomprometido. Este trabalho discute a leitura e especificamente 
a leitura literária e o letramento literário ${ }^{3}$. O letramento literário é fundamental para que o indivíduo tenha uma experiência estético-literária que permita compreender e transformar o mundo através do discurso simbólico e humano. A leitura literária quando realizada adequadamente poderá se transformar no início de uma longa e prazerosa caminhada em outras leituras. É por isso que a literatura precisa ter um lugar especial nas escolas, que reforce o letramento para que os alunos possam, entre outras coisas, se tornarem aptos a apreender o conteúdo de ensino e transformá-lo em competências.

Nesse sentido, chamamos a atenção para a biblioteca escolar como um espaço de estudo e acesso ao conhecimento. A biblioteca escolar tem função educativa, ao mostrar para o aluno a diversidade de saberes e de pontos de vista, além dos múltiplos esforços em compreender o mundo. Dessa forma, a biblioteca pode se converter num mecanismo de transformação das relações entre alunos, professores, bibliotecários, auxiliares, dentre outros, proporcionando mediações e favorecendo o ganho da autonomia e envolvimento de todos os agentes envolvidos com a leitura.

Por fim, é importante ressaltar que se faz necessário continuar investigando/estudando as práticas pedagógicas/educativas em relação à mediação de leitura. Pensar em formações de leitores que estejam realmente imbuídas em formar leitores livres, no sentido amplo da palavra. Dessa forma, os alunos-sujeitos aprenderão a interagir melhor com o mundo, poderão conhecer os mecanismos de coerção aos quais estão subordinados, e, conforme preconiza Bourdieu (2007), exatamente porque conhecemos as leis de reprodução - "as formas pelas quais ela se efetiva - é que passamos a ter alguma possibilidade de minimizar os efeitos da ação reprodutora da instituição escolar" (p. 77). Ao minimizar estes efeitos, os alunos-sujeitos poderão tornar-se agentes de sua própria leitura.

\section{RENATA JUNQUEIRA}

Doutora em Letras pela UNESP (2000), mestre em Linguística e Letras pela PUCRS (1990). É livre-docente pela UNESP e professora visitante da Universidade do Minho-PT. Atua como professora colaboradora no Programa de Pós-graduação em Letras da Universidade Federal do Espírito Santo (UFES). 


\section{REFERÊNCIAS}

AGUIAR, Vera Teixeira de. Biblioteca e formação de leitores. Cadernos de Educação Básica, São Paulo, v. 4, p. 99-103, 1994.

AGUIAR, Vera Teixeira de. O caminho dos livros: da biblioteca à comunidade. In: AGUIAR, V. T.; MARTHA, Alice A. P. (org.) Territórios da leitura: da literatura aos leitores. São Paulo: Cultura Acadêmica; Assis: ANEP, 2006, p. 255-267.

AMORIM, Galeno (Org.) Retratos da leitura no Brasil. São Paulo: Imprensa Oficial: Instituto Pró-livro, 2010.

BRASIL. Parâmetros Curriculares Nacionais: terceiro e quarto ciclos do ensino fundamental: introdução aos Parâmetros Curriculares Nacionais. Brasília: MEC/SEF, 1998.

BOURDIEU, Pierre Os três estados do capital cultural. In: NOGUEIRA, Maria Alice; CATANI, Afrânio (Org.). Escritos de educação. 9. ed. Petrópolis: Vozes, 2007. (p.7179).

BURLAMAQUE, Fabiane Verardi. Os primeiros passos na constituição de leitores autônomos: a formação do professor. In: TURCHI, Maria Zaira; SILVA, Vera M. T.; (Org). Leitor formado, leitor em formação: a leitura literária em questão. São Paulo: Cultura Acadêmica, 2006.p.79-91.

BORTOLIN, Sueli. A leitura literária nas bibliotecas Monteiro Lobato de São Paulo e Salvador. 2001. 233f. Dissertação (Mestrado em Ciência da Informação) Faculdade de Filosofia e Ciências, Universidade Estadual Paulista, Marília.

CARVALHO, Maria Conceição. Escola, biblioteca e leitura. In: CAMPELLO, B. S. A biblioteca escolar: temas para uma prática pedagógica. Belo Horizonte: Autêntica, 2002. p. 13-15.

CARVALHO, N. C. Leitura literária: o processo de comunicação literária e a formação do leitor crítico. apud: AGUILERA, V. A.; LIMOLI, L. (Org.). Entrelinhas, entretelas: os desafios da leitura. Londrina: Ed. UEL, 2001. p. 53-63.

CERRILLO, P. C.; YUBERO S. (Orgs.). La formación de mediadores para a promoción de la lectura: contenidos de referencia del Máster de Promoción de la Lectura y Literatura Infantil. Cuenca: CEPLI, 2003.

CORRÊA, Hércules Tolêdo. Entrevista a Begma Tavares Barbosa. Revista Práticas de Linguagem, Juiz de Fora, UFJF, v. 2, n. 2, jul./dez. 2012.

CORRÊA, Hércules e PAIVA, Aparecida. Literatura \& Alfabetização: impasses e possibilidades. Via Atlântica, São Paulo, USP, n. 28, 177-196, dez. 2015. 
CORREAA, Hércules. Letramento literário e escola. In: CYRANKA, Lúcia e MAGALHÃES, Tânia (Orgs.) Interação, linguagem e ensino. Juiz de Fora: UFJF, 2016-2017 (no prelo).

COSSON, Rildo. Letramento literário: teoria e prática. 2. ed. São Paulo: Contexto, 2006.

COSSON, Rildo. A prática da leitura literária na escola: mediação ou ensino?

Nuances: estudos sobre Educação, Presidente Prudente-SP, v. 26, n. 3, p. 161-173, set./dez. 2015.

GIROTTO, Cyntia G. G. S. e SOUZA, Renata Junqueira de. Estratégias de leitura: para ensinar alunos a compreender o que leem. In: SOUZA, Renata Junqueira de et al. Ler e compreender: estratégias de leitura. Campinas, SP: Mercado de Letras, 2010.

GOMES, Luciano F. e BORTOLIN, Sueli. Biblioteca escolar e a mediação da leitura. Semina: Ciências Sociais e Humanas, Londrina, v. 32, n. 2, p. 157-170, jul./dez. 2011.

LOURENÇO FILHO, Manoel Bergstrõm. Como aperfeiçoar a Literatura infantil. Revista Brasileira. Rio de Janeiro, v. 3, n. 7, p. 146-169, 1943.

MARQUES NETO, José Castilho (Org.). PNLL: textos e história. São Paulo: Cultura Acadêmica Editora, 2010.

MARTINS, Aracy. O que se aprende com a literatura na escola. In: PAIVA, A. (Org.). Leituras literárias: discursos transitivos. Belo Horizonte: Ceale, 2008.

MOTTA, Diana da. Biblioteca escolar: orientações básicas para organização e funcionamento. Revista do Professor, Porto Alegre, v. 15, n. 58, p. 21-24, abr./jun. 1999.

PAIVA, Aparecida (Org.). Literatura fora da caixa: o PNBE na escola - distribuição, circulação e leitura. São Paulo: Ed. Unesp, 2012.

PAULINO, Maria das Graças. Letramento literário: por vielas e alamedas. Revista da Faced/UFBA, Salvador, n.5, p. 56, 2001.

PAULINO, Graça; COSSON, Rildo. Letramento literário: para viver a literatura dentro e fora da escola. In: RÖSING, Tânia M. K.; ZILBERNAM, Regina (Orgs.). Escola e leitura: velha crise, novas alternativas. São Paulo: Global, 2009.

PERROTTI, Edmir. Confinamento cultural, infância e leitura e leitura. São Paulo: Summus, 1990.

SILVA, Waldeck C. Miséria da biblioteca escolar. São Paulo: Cortez, 1995. 
SILVA, Ezequiel Theodoro da. $O$ ato de ler: fundamentos psicológicos para uma nova pedagogia da leitura. 10. ed. São Paulo: Cortez, 2005.

SILVA, Rovilson J. Biblioteca escolar e a formação de leitores: o papel do mediador de leitura. Londrina: EDUEL, 2009.

SILVA, Lílian da, FERREIRA, Norma e SCORSI, Rosália. Formar leitores: desafios da sala de aula e da biblioteca escolar. In: SOUZA, Renata Junqueira de (Org.).

Biblioteca escolar e práticas educativas: o mediador em formação. Campinas: Mercado das Letras, 2009.

SOARES, Magda. Letramento: um tema em três gêneros. Belo Horizonte: Autêntica, 1998.

SOARES, Magda B. Práticas de leituras literárias nas séries finais do ensino fundamental. In: COLÓQUIO INTERNACIONAL DE ESTUDOS LINGUÍSTICOS E LITERÁRIOS, 4, 2010. Maringá. Anais... Maringá: UEM, 2010.

SOLÉ, Isabel. Estratégias de leitura. Porto alegre: Artes médicas, 1998.

UMBELINO, Janaina Damasceno. A narração de histórias no espaço escolar: a experiência do Pró-Leitura. Dissertação de mestrado, UFSC, Florianópolis, 2005.

VAZ, Márcia Cristina Dias. Gestão Participativa. Disponível em:

http://www.webartigosos.com/articles/5895/1/gestao-participativa/pagina1.html. Acesso em novembro de 2016.

ZILBERMAN, Regina (Org.). Leitura em crise na escola: as alternativas do professor. 2. ed. Porto Alegre: Mercado Aberto, 1982. 